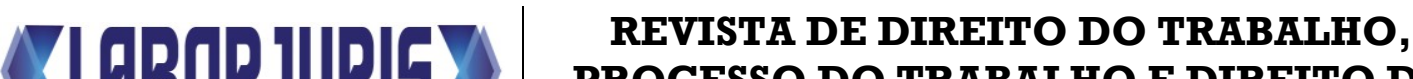 PROCESSO DO TRABALHO E DIREITO DA SEGURIDADE SOCIAL

\section{LA FORMACIÓN LABORAL DE JÓVENES EN BRASIL Y EN PERÚ 1}

\author{
Miguel F. Canessa Montejo ${ }^{2}$
}

Luis Mendoza Legoas ${ }^{3}$

\section{Resumen}

La formación laboral juvenil es una de las materias principales de la política de empleo, especialmente por las altas cifras de desempleo que sufre este grupo etario en nuestras sociedades. Por lo general, se identifica a su baja calificación laboral como la causa principal de su desempleo. Sin embargo, se dejan de lado aspectos fundamentales del mercado de trabajo como la estructura productiva del país, el nivel educativo o el ordenamiento laboral. Para paliar esta situación, los Estados buscan subsanarlo por medio de políticas laborales que conjuguen la formación laboral y la práctica profesional, es decir, promover que los jóvenes adquieran sus habilidades laborales a través de sus propias actividades al interior de una empresa o una entidad pública, de modo que al egresar de este período educativo laboral cuenten con las calificaciones y la experiencia que facilite su contratación. El presente estudio se centra en analizar las políticas de formación laboral juvenil implementado por Brasil y Perú, comparando los aspectos jurídicos en el diseño normativo de ambas regulaciones laborales, identificando las virtudes y los desaciertos en su planteamiento, así como midiendo, en el caso peruano, su impacto en el empleo juvenil y concluyendo con una serie de propuestas que mejoren la política laboral en la materia.

\section{Palabras claves: Formación laboral; Jóvenes; Brasil; Perú; Política laboral;}

\section{Resumo}

A formação profissional para jovens é um dos principais temas da política de emprego, principalmente devido às altas taxas de desemprego sofridas por essa faixa etária em nossas sociedades. Geralmente, a baixa qualificação no trabalho é identificada como a principal causa do desemprego. No entanto, aspectos fundamentais do mercado de trabalho são deixados de lado, como estrutura produtiva do país, nível educacional ou legislação trabalhista. Para aliviar essa situação, os Estados buscam corrigi-la por meio de políticas trabalhistas que combinam treinamento profissional e prática profissional, ou seja, promover que os jovens adquiram suas habilidades profissionais por meio de suas próprias atividades em uma empresa ou entidade pública, para que, ao se formarem nesse período de educação trabalhista, possuam as qualificações e a experiência que facilitam sua contratação. Este estudo se concentra na análise das políticas de treinamento para trabalho juvenil implementadas pelo Brasil e pelo Peru, comparando os aspectos legais no desenho normativo de ambas as regulamentações trabalhistas, identificando os pontos fortes e fracos de sua abordagem, bem como medindo, no caso peruano, seu

\footnotetext{
${ }^{1}$ Una primera versión fue desarrollada para el Proyecto Algodón con Trabajo Decente (GLO/14/45/BRA - Cooperación SurSur para la promoción del trabajo decente en los países productores de algodón en África y América Latina), implementado por la Organización Internacional de Trabajo (OIT) y por la Agencia Brasileña de Cooperación (ABC) del Ministerio de Relaciones Exteriores de Brasil con recursos del Instituto Brasileño del Algodón (IBA).

${ }^{2}$ Miguel F. Canessa Montejo - Abogado y Sociólogo por la Pontificia Universidad Católica del Perú. Doctor en Derecho por la Universidad Carlos III de Madrid. Profesor universitario y consultor internacional. E-mail: mcanessa@pucp.edu.pe.

${ }^{3}$ Luis Mendoza Legoas - Abogado por la Pontificia Universidad Católica del Perú. Magíster en Relaciones Industriales y de Empleo por la Universidad de Turín y el Centro Internacional de Formación de la Organización Internacional del Trabajo E-mail: lmendozalegoas@pucp.pe
} 
impacto no emprego jovem e concluindo com uma série de propostas que melhoram a política trabalhista nessa área.

Palavras chaves: Formação profissional; Jovens; Brasil; Peru; Política trabalhista;

\section{INTRODUCCIÓN}

El presente trabajo ofrece una reflexión sobre la legislación referida a la formación de personas jóvenes en el trabajo, estableciendo en una primera entrada legal una visión comparativa entre la normativa peruana y la legislación brasilera sobre el particular (en especial, la Ley 10.097). Luego, en la segunda parte del trabajo, se ofrecerá una visión peruana que combinará la información estadística disponible con el examen jurídico sobre la norma, en particular la Ley 28518, Ley de Modalidades Formativas Laborales (en adelante LMFL).

En Perú, el Plan Nacional de Competitividad y Productividad, aprobado por el Decreto Supremo 237 2019-EF, se ha constituido como un importante instrumento de política laboral, el mismo que ha sido observado por parte de la sociedad civil como un marco flexibilizador o, al menos, propiciador de la reducción de los estándares de las normas de trabajo.

Este Plan Nacional peruano plantea, como su quinta medida principal dentro del Objetivo Prioritario $5,{ }^{4}$ la mejora del marco legal de las modalidades formativas, considerando la alta tasa de desempleo de los jóvenes - que ya venía creciendo sostenidamente antes de la irrupción de la pandemia del covid19-, el alto índice de la inadecuación profesional de ese grupo de personas, y el escaso uso de la LMFL por las empresas.

De este modo, el Plan Nacional abre el debate sobre la reforma de la referida Ley. Sin embargo, ese debate debe asentarse sobre la identificación de las causas del fracaso de su aplicación en el mercado de trabajo peruano. No basta una lectura legal que, de manera abstracta, aborde el empleo juvenil peruano sino viene acompañado con el respaldo del análisis socio jurídico de la aplicación de la Ley.

\section{RASGOS DE CONTRASTE: LEGISLACIÓN PERUANA Y BRASILERA SOBRE FORMACIÓN PROFESIONAL Y TRABAJO}

${ }^{4}$ El Objetivo Estratégico 5 plantea crear las condiciones para un mercado laboral dinámico y competitivo para la generación de empleo digno. 
Partimos desde una entrada constitucional de lo formativo en el mundo del trabajo. Existen semejanzas notorias en la conceptuación de la formación profesional dentro de los derechos fundamentales en el trabajo que se advierten en las normas que pre ordenan la legislación peruana y la brasilera. Así, la formación profesional puede ser concebida dentro de la categoría de los "derechos fundamentales", al tener un contenido implicado en los derechos al trabajo y a la educación, reconocidos ambos en las cartas constitucionales citadas.

En la Constitución Política del Perú de 1993 encontramos que la educación tiene como finalidad el "desarrollo integral de la persona humana" (artículo $13^{\circ}$ ), reconociéndose explícitamente que la educación "prepara para la vida y el trabajo y fomenta la solidaridad" (artículo 14). También se plantea la importancia de la educación adecuada sea impartida sin que las limitaciones económicas, mentales o físicas sean impedimentos (artículo $16^{\circ}$ ). Enunciativamente se reconoce también que el Estado promueve el progreso social y económico a través de políticas de educación para el trabajo (artículo $23^{\circ}$ ), lo que se inserta dentro del modelo enunciado de "Economía Social de Mercado" que tiene dentro de sus principales áreas de actuación, precisamente, a la educación (artículo 58²).

De otro lado, la Constitución Política de 1988 de la República Federativa de Brasil reconoce a la educación y al trabajo como derechos sociales (artículo $6^{\circ}$ ) que tienden a la mejora de la condición social de trabajadores urbanos y rurales (artículo $7^{\circ} .4$ ). Además, la norma fundamental brasileña reconoce que la educación es promovida e incentivada, tendiendo al pleno desarrollo de la persona en su calificación para el trabajo (artículo 205). Asimismo, se reconoce a la "formación para el trabajo" como un eje del plan nacional de educación (artículo $214^{\circ}$, inciso 4 ) y como parte de los programas de atención para los portadores de discapacidades (artículo $227^{\circ}$ numeral 1 , inciso 2 ).

De esta manera, el derecho a la formación recae en la esfera de obligaciones del Estado, pero no puede agotarse de ninguna forma en las prestaciones estatales. Como quiera que se trata de un derecho que encuentra sentido dentro del mundo del trabajo, las obligaciones que este derecho supone recaen en los empresarios y los centros de formación, que asumen la posición jurídica de "sujetos obligados" frente al titular de este derecho: el joven que necesita de la formación, ya no previa sino coetánea a su incorporación al trabajo.

En Perú, la LMFL establece una serie de principios de los procesos formativos: i) establece a la comprensión, por parte del beneficiario del proceso formativo, del medio social y laboral; ii) el trato en igualdad y sin discriminación; y iii) la adecuación y utilidad práctica de la formación impartida en las 
empresas. A su vez, el Decreto Supremo 007-2005-TR es el Reglamento de la Ley (en adelante, RLMFL) que precisa una serie de regulaciones en la materia.

Las posiciones subjetivas de quienes ocupan el lugar de "acreedor" de formación profesional (el joven que busca incorporarse al mercado de trabajo) y la de deudores de formación profesional (la empresa y el centro de formación, en distinta medida) forman un tipo de vínculo jurídico cuyo elemento esencial es, qué duda cabe, el formativo. No puede, por ello, confundirse a esta forma de vinculación con la mera prestación personal de servicios por la que una de las partes pone a disposición de la otra su actividad para un fin económico determinado. Esta distinción es clave pues mientras que en el primer caso se encuentra el elemento formativo como factor esencial, en el otro se carece totalmente de esa finalidad. Mientras que en la formación profesional suele existir una relación tripartita, en la prestación de servicios pura y simple se suelen trabar relaciones bilaterales.

Por esos motivos, la regulación de la formación profesional debe ser lo suficientemente clara al establecer los objetos de uno y otro tipo de institución. Por ejemplo, desde el punto de vista del Derecho contractual, la "causa" del contrato celebrado entre las partes debería esbozar claramente las dimensiones formativas y productivas, que no pueden ser soslayadas sin sacrificar con ello la veracidad del sentido práctico que tienen los convenios de formación en el mercado de trabajo.

En Brasil, la legislación sobre modalidades formativas se encuentra reunida en la Ley 10.097, del año 2000 y el llamado "contrato de aprendizaje" se encuentra reglamentado por el Decreto $N^{\circ} 5.598$, del 1 de diciembre de 2005. A diferencia de lo que acontece en Perú, la formación para el empleo sí forma parte de la legislación laboral, considerándose a ese tipo contractual como un contrato especial de trabajo (en Perú se denominaría un "régimen laboral especial"). La importancia de esto se grafica bien al observarse que en el grupo etario de jóvenes que pueden trabajar (hasta los veinticuatro años), el grupo de ellos que está contratado como aprendiz es equivalente, aproximadamente, al cinco por ciento $(5 \%) .^{5}$

\footnotetext{
${ }^{5}$ Normas mencionadas entre varias otras relevantes sobre el fenómeno, como la Ley $\mathrm{N}^{\circ} 8.036$, de 11 de mayo de 1990 , "Dispone sobre el Fondo de Garantía del Tiempo de Servicio y da otras providencias"; el Decreto $\mathrm{N}^{\circ} 6.482$, de 12 de junio de 2008, "Regula los artículos 3d y 4 de la Convención 182 de la Organización Internacional del Trabajo (OIT), que trata sobre la prohibición de las peores formas de trabajo infantil y la acción inmediata para eliminar de ellos , aprobado por el Decreto Legislativo 178, de 14 de diciembre de 1999, y promulgada por el Decreto 3597, de 12 de septiembre de 2000, y otras medidas"; y el MTE N 273, "Portaria do Ministério do Trabalho e Emprego", de 23 de Abril de 2012.
} 
Aquí salta a la vista un primer carácter distinguidor: mientras que en Brasil unas pocas normas de ámbito delimitado complementan al principal cuerpo normativo sobre la materia; en Perú, las normas sobre modalidades formativas tienen una alta dispersión. Una revisión completa de las normas aplicables a las modalidades formativas peruanas incluye, junto con la propia LMFL y el RMFL, a más de una docena de normas complementarias. ${ }^{6}$

Luego, otra diferencia notable es que, a diferencia de lo anotado respecto del caso peruano, la Ley 10.097 si prevé la aplicación de incentivos fiscales y laborales para la contratación de aprendices en las empresas, por hasta 24 meses.

\section{1 ¿El elemento formativo es un factor excluyente de la relación de trabajo?}

La medida de política fiscal y social anotada sobre Brasil se explica por el hecho de que la forma de contratación de personas en formación para el empleo está dispuesta dentro de un sistema obligatorio de cuotas, dentro del régimen laboral común. Conforme con estadísticas oficiales, se tiene que entre 2005 y 2013 el Brasil alcanzó un total de 1'702,365 aprendices admitidos (Leite 2015: 65).

En cambio, las normas sobre formación profesional en el Perú excluyen explícitamente a este segmento de la población económicamente activa de la aplicación de la legislación laboral. Así, se ha regulado un estatuto totalmente propio para esta categoría de prestadores de servicios.

Volviendo a la teoría del Derecho del Trabajo, la legislación laboral se aplica allí donde se verifica la existencia de un contrato de trabajo, el mismo que se puede definir como un contrato-realidad. La

\footnotetext{
${ }^{6}$ Nos referimos al Decreto Supremo 002-97-TR que aprobó el Texto Único Ordenado del Decreto Legislativo 728, Ley de Formación y Promoción Laboral, Decreto Supremo 001-96-TR que aprobó el Reglamento de la Ley de Fomento al Empleo; Decreto Ley 20151 que dictan las normas para regular el Aprendizaje en el Sector Industria y Comercio que se controla a través del SENATI; la Ley 30512 sobre instituto y escuelas de educación superior; el Decreto Legislativo 1375 sobre la modificación de la Ley General de Educación; el Decreto Legislativo 1378 sobre el certificado único laboral para jóvenes; el Decreto Supremo 003-2008-TR sobre las jornadas máximas de modalidades formativas reguladas por la Ley 28518 así como de las prácticas preprofesionales de derecho y de internado en ciencias de la salud; el Decreto Supremo 014-2018-TR que aprueba el Reglamento del Decreto Legislativo 1378 sobre el certificado único laboral para jóvenes; la Resolución Ministerial 069-2007-TR (de fecha 15 de marzo de 2007), que aprobó la norma "Dictan disposiciones complementarias para el registro de planes y programas, y aprueban modelos y formatos sobre modalidades formativas laborales"; la Resolución Ministerial 167-2010-TR (de fecha 19 de julio de 2010), que aprobó la norma "Aprueban listado de ocupaciones básicas y operativas modalidad formativa laboral de capacitación laboral juvenil"; la Resolución Directoral 055-2014-MTPE/3/19 (de fecha 29 de agosto de 2014), que aprobó el "Catálogo nacional de perfiles ocupacionales (cualificaciones)"; la Resolución Ministerial 017-2016-TR (de fecha 1 de febrero de 2016), que aprobó el "Plan de actuación de capacitación dual para la mejora de la empleabilidad, a través de la capacitación dual"; y la Resolución Ministerial No 205-2011-TR, que aprobó la Directiva General No 1-2011-MTPE/3/19 "Canalización de Convenios de Modalidades Formativas Laborales hacia el Sistema de Inspecciones".
} 
situación jurídica calificada en el Derecho peruano como una relación de trabajo es aquella en la que concurren tres elementos esenciales: una prestación personal, una remuneración y fundamentalmente- la existencia de subordinación jurídica o dependencia del poder de dirección respecto de la contraparte contractual.

No obstante, el legislador peruano ha considerado que la presencia del elemento formativo excluye de por sí la aplicación de la legislación laboral en las modalidades formativas, sin mayor graduación ni reconocimiento de posibles "zonas grises". Así, al revisarse la LMFL, se observa que algunas modalidades tipificadas contemplan al hecho de que un Centro de Formación Profesional exija la realización de determinada modalidad formativa como justificante de la existencia de la relación contractual de formación.

A fin de apuntalar ese criterio regulatorio, se observa en la LMFL y en sus normas reglamentarias que hay un evidente esfuerzo del legislador por evitar calificar determinados elementos del vínculo jurídico resultante de la prestación de servicios bajo los términos utilizados en la relación de trabajo. Así, se hace referencia a la retribución pagada como "subvención" en vez de "remuneración"; la "subvención adicional" sustituye a las "gratificaciones legales" (aunque la oportunidad de pago varía, ambas comparten la característica de ser un beneficio otorgado semestralmente equivalente al monto de la retribución mensual); las "vacaciones" son llamadas meramente "descanso" (y se reconocen en una fórmula reducida con respecto a la legislación laboral común); y la "jornada de trabajo" se denomina en la LMFL como “jornada formativa”.

Para algunos analistas de la legislación peruana, la exclusión laboral está aparejada con la creación de ciertos tipos de modalidades formativas que estarían desvirtuadas desde su formulación en el texto normativo. Tal sería el caso de la reinserción laboral (artículo 29 y siguientes de la LMFL), donde se observa que su ámbito objetivo está focalizado en los desempleados mayores de 45 años. La modalidad carece del elemento formativo del resto de los otros tipos reconocidos en la LMFL, por lo que su justificación dentro de la categoría de los contratos formativos es insostenible (Arce 2008: 271). En ese sentido, se ha destacado que el efecto excluyente de la legislación laboral puede ser mal utilizado bajo una supuesta "reinserción laboral" que, paradójicamente, resulta en una relación contractual desprovista de los beneficios de la legislación laboral. Sin embargo, esta figura podría encontrarse sustentada en los "castigos salariales" y hasta la estigmatización social que pueden sufrir los trabajadores cuyas capacidades específicas se han desarrollado en puestos de trabajo adscritos a determinadas actividades económicas que experimentan periodos de crisis (Yamada y Cárdenas 2009: 
317). El desplazamiento de estas personas a nuevos empleos podría implicar la necesidad de una nueva formación profesional que pueda impactar positivamente en los ingresos obtenidos tras el desempleo. No nos parece, vistas estas válidas observaciones, que la dimensión laboral y la formativa sean irreconciliables. Al contrario, resulta evidente que la etapa formativa puede desarrollarse en el marco de la relación laboral sin demasiados inconvenientes: siempre la parte empleadora podrá ejercitar la facultad directriz para poder adoptar las decisiones que resulten necesarias para organizar, fiscalizar o (en algún caso) sancionar los incumplimientos. En ese sentido, considerando las herramientas contractuales que la legislación laboral peruana otorga a los empleadores, se puede considerar que el elemento formativo podría justificar un contrato temporal, cuya vigencia sea congruente con la duración del plan específico de formación que pueda contemplarse para el caso en concreto.

Sin embargo, no puede dejar de reconocerse que el efecto de esta regulación en el mercado peruano ha generado un incentivo para que las empresas y el propio Estado ${ }^{7}$ se sirvan de mano de obra inexperta, muchas veces sin atribuir una real importancia al elemento formativo. Se mantienen así las objeciones que desde la emisión de la LMFL y su Reglamento se han planteado sobre la verdadera intención del legislador y de sus efectos distantes a un genuino fomento del empleo y de la capacitación laboral (Toyama 2008: 116). Este enfoque normativo tiene efectos prácticos muy claros. Por ejemplo, analizando las estadísticas laborales de 2013, los practicantes tuvieron, en promedio, uno de los ingresos laborales más bajos del ingreso laboral mensual promedio de 715 soles, ocupando junto con las trabajadoras del hogar el penúltimo peldaño en comparación con el promedio de la población económicamente activa ocupada que fue de 1,053 soles (Cuadros 2016: 56). Hay que tener presente que la remuneración mínima en 2013 fue de 750 soles, con lo que el ingreso promedio de los practicantes fue inferior a ese piso salarial.

De otro lado, el elemento formativo en la LMFL y el RLMFL no aparece aparejado con un derecho de preferencia de los beneficiarios de dicha forma de contratación. La falta de esa previsión legal resulta un punto en contra en la valoración de esta normativa como herramienta para la incorporación laboral de las personas que son contratadas bajo modalidades formativas, ya que no existe un mecanismo regulatorio que al menos favorezca su participación en concursos por vacantes en las mismas empresas donde prestaron servicios.

${ }^{7}$ El Decreto Legislativo 1401 regula el Régimen Especial de las modalidades formativas de servicios en el sector público. 
En general, existe una percepción favorable en el traslado paulatino o gradual de las modalidades formativas hacia el régimen laboral común. No obstante, se entiende que dicho escenario podría acabar con la efectividad de las antedichas formas de contratación de jóvenes en formación, al añadirse a tales contratos más beneficios, lo que haría menos atractivo el contar con ese personal (ya que no poseerían todas las competencias deseables, en comparación de aquel más antiguo). En todo caso, se puede plantear que las modalidades formativas podrían tener un alcance distinto, por ejemplo, con nuevos proyectos normativos que buscan regular el empleo juvenil, sin caer en regulaciones similares a la Ley Pulpín ${ }^{8}$.

\subsection{La regulación de los parámetros de lo formativo}

En Brasil, ciertos mecanismos que dan a entender que la finalidad formativa tiene límites claros que deben ser considerados por los empleadores. Así, el hecho de que se proscriba cualquier forma de trabajo fuera de la jornada establecida apuntala la idea de una necesaria observancia del plan formativo dentro de los parámetros de una jornada rígidamente establecida. Además, esta restricción aparta a los jóvenes en formación de la fuerza de trabajo recurrible ante necesidades productivas extraordinarias, lo que cumple bien con justificar su tratamiento como "aprendices" y no como meros "trabajadores". En línea con aquella preocupación, se especifican aspectos relevantes para el cumplimiento del programa de aprendizaje en lo que tiene que ver con las actividades teóricas y prácticas. Así, la legislación brasilera prevé que el ambiente físico sea adecuado y, entre otros aspectos, el Decreto $\mathrm{N}^{\circ}$ 5.598 se ocupa de reglamentar la dinámica administrativa para las autorizaciones correspondientes, según si las clases prácticas ocurren en la entidad que provee la formación profesional o en el establecimiento contratante (empresa).

Si bien, al igual que a la par de lo ocurrido en el Perú, la regulación del contrato de aprendizaje ha sido calificada como una forma de flexibilización de la utilización de la fuerza del trabajo en el Brasil (Gomes 2005: 12), parece ser que el devenir de esta figura en el tiempo ha sido reencausado hasta conciliar la finalidad formativa enunciada con la tutela de los trabajadores aprendices. Prueba de esto es que el Decreto $\mathrm{N}^{\circ} 5.598$ sancione con la nulidad del contrato de aprendizaje (estableciéndose una relación de trabajo) a todos los supuestos de incumplimiento de las normas heterónomas y previsiones del contrato de aprendizaje. Esta sanción (que se remite al artículo $9^{\circ}$ del Decreto Ley $\mathrm{N}^{\circ} 5.452$, que aprueba la

\footnotetext{
${ }^{8}$ La Ley Pulpín hace referencia a la norma aprobada por el Congreso peruano que reguló la contratación laboral de jóvenes y el término Pulpín alude a un jugo envasado que consumen los adolescentes, con lo que la connotación es peyorativa porque se refiere a que los jóvenes son tratados como adolescentes, a los que se les impone reglas sin consultar.
} 
consolidación de las leyes laborales) pone en relieve la tajante preocupación por la veracidad de la finalidad formativa declarada por las partes firmantes del contrato de aprendizaje.

Por el lado peruano, ni la LMFL ni el RLMFL contemplan parámetros que aclaren la duración de la formación dentro de la jornada que se puede llegar a cumplir. No se observan porcentajes del tiempo total de la jornada que se refieran siquiera de manera sugerida. Asimismo, tampoco existe una reglamentación de los controles, evaluaciones, supervisión y retroalimentación que debería existir dentro de una relación formativa.

El problema de este modelo es que impide un control permanente dentro de la misma empresa, que pueda validar los progresos del joven dentro de las etapas formativas. Sin obligaciones claras en materia formativa para el centro productivo que alberga al joven en formación, resulta difícil suponer que pueda interiorizarse algún incentivo real para garantizar que la formación tenga controles de calidad y que admita adecuaciones para atender necesidades especiales de parte de los beneficiarios de las modalidades formativas.

La LMFL confía este papel de control a los centros de formación, aunque tampoco están claras las sanciones que pudieran recibir por el incumplimiento o deficiente cumplimiento de la responsabilidad de verificar que la modalidad formativa cumpla, efectivamente, con esa finalidad y que no esconda una relación de trabajo sin costos laborales. Tampoco se conoce información estadística que permita conocer la incidencia de la fiscalización laboral en las modalidades formativas o si se han impuesto sanciones administrativas por infracciones a la LMFL, lo que se tiene registrado son el número de inspecciones anuales realizadas por capacitación y modalidades formativas.

En el mejor de los casos, este modelo legal permite que se ejercite un control ex post que difícilmente puede abarcar el propio centro de formación. Aunque la ley prevé que las entidades educativas deben ejercer una labor de fiscalización activa que garantice la efectividad de los derechos de los beneficiarios de estas modalidades, la participación real de dichos centros formativos muchas veces se limita al cumplimiento de los requisitos formales (suscripción de los programas de capacitación y supervisión de las empresas). Por ello, en la generalidad de los casos, corresponde a la Autoridad de Trabajo intervenir en estos casos como fiscalizador. Lo cierto es que resulta difícil asegurar la efectividad y el cumplimiento de los derechos en las modalidades formativas, toda vez que los centros de formación -actores clave para la eficacia de dicho propósito- no manifiestan mayor interés en desarrollar este tipo de acciones. 


\subsection{Principales derechos específicos de los beneficiarios de modalidades formativas (Perú) y los} contratos de aprendizaje (Brasil)

La legislación peruana ordena que los empresarios o las entidades estatales sujetas al régimen laboral de la actividad privada que celebren convenios de formación deben cumplir con una serie de prestaciones por mandato legal. Por tanto, compararemos a tales mandatos con los propios de la relación de trabajo especial regulada en el Brasil. Así, reconocemos en las modalidades formativas peruanas a la prestación de servicios de personas dentro de unidades productivas, lo que de forma indudable los convierte también en titulares de una serie de derechos de carácter general. ${ }^{9}$

\subsubsection{La limitación de la jornada}

En Brasil, el tiempo máximo de trabajo de los aprendices está fijado en el Decreto $\mathrm{N}^{\circ} 5.598$ en seis horas diarias, que comprenden a las actividades teóricas y prácticas. No obstante, este límite puede extenderse hasta las ocho horas diarias para aprendices que hayan completado la educación primaria, si en ellas se consideran las horas destinadas al aprendizaje teórico. Asimismo, existe una prohibición expresa de la prórroga de la jornada y la compensación de esta.

De otro lado, en el caso de los menores de dieciocho años, se prevé que, si se le emplea en más de un establecimiento, las horas totales de trabajo en cada uno se considerarán dentro de los mismos límites enunciados en el párrafo anterior.

Junto con esto, se establece un régimen vacacional especial para los aprendices brasileros: debe coincidir preferentemente con las vacaciones escolares. En todo caso, se prohíbe al empleador el programar el descanso vacacional en un periodo distinto al definido en el programa de aprendizaje.

En el caso peruano, la LMFL establece diversos parámetros para las modalidades tipificadas, siendo el tope máximo de la jornada similar al régimen general, es decir, 8 horas diarias o 48 semanales; salvo el caso del aprendizaje con predominio en la empresa y los convenios de prácticas preprofesionales (6 horas diarias o 30 semanales). En el caso de los convenios de pasantía con estudiantes de últimos grados de educación secundaria, le corresponde al Ministerio de Educación establecer el límite aplicable.

\footnotetext{
${ }^{9}$ Entre tales otros derechos, citamos como ejemplos a la extensión del deber jurídico de prevención, impuesto por la Ley $\mathrm{N}^{\circ}$ 29873, Ley de Seguridad y Salud en el Trabajo; y la protección dispensada hacia los jóvenes contratados bajo modalidades formativas a través de la Ley $\mathrm{N}^{\circ} 27942$, Ley de Prevención y Sanción del Hostigamiento Sexual, cuerpo normativo que los considera miembros de un "grupo vulnerable" frente al acoso sexual.
} 
Inicialmente, por efecto del artículo $52^{\circ}$ de la LMFL se consideró que el exceso al horario habitual de la empresa, así como la jornada en horario nocturno sin autorización administrativa suponían formas de incumplimiento que no configuraban un perjuicio grave contra el beneficiario. Sin embargo, la dación del Decreto Supremo 003-2008-TR sancionó con nulidad al convenio de modalidades formativas cuando se determine el exceso en la jornada (inclusive si concurriese el consentimiento del beneficiario de la formación).

Por ese motivo, el exceso en la jornada de los beneficiarios de modalidades formativas ha sido objeto de cuestionamientos en la vía jurisdiccional. Inclusive, el Tribunal Constitucional peruano ha resuelto indicando que la evidencia de trabajo por encima de dicho tiempo acredita la desnaturalización de las modalidades formativas (TCP 2013: Considerando 10).

\subsubsection{Monto mínimo de la retribución percibida}

En forma general, podemos afirmar que el criterio común aplicado por las legislaciones de ambos países es la equiparación con la remuneración mínima.

En Brasil, el trabajo del aprendiz es retribuido conforme con el "salario mínimo hora", que es el correspondiente a los trabajadores que poseen una jornada inferior a ocho horas por día. Actualmente el salario mínimo es de 1045 reales (194 dólares mensuales, aproximadamente) ${ }^{10}$.

En Perú, el equivalente a la remuneración mínima es pagado de forma condicionada a que el beneficiario del convenio cumpla con la jornada máxima prevista en la ley. La duración inferior de la jornada motiva el pago de una subvención proporcional.

No obstante, en el país andino se aprecia que se prevén reglas especiales para los casos de pasantía de estudiantes de educación secundaria (no menos del 5\% de la remuneración mínima) y las demás formas de pasantías, donde la subvención alcanza el 30\%. Asimismo, la reinserción laboral es retribuida con no menos de dos remuneraciones mínimas.

\subsubsection{Limitación del plazo de duración del contrato suscrito con el beneficiario correspondiente} La duración de la vigencia del convenio es un asunto relevante para el otorgamiento de estabilidad al contrato, lo que brinda una estela de protección al prestador de servicios semejante a la estabilidad

\footnotetext{
${ }^{10}$ Actualizado al 2 de mayo de 2020.
} 
laboral (caso peruano) o que abiertamente implica una forma de tutela en la protección en el trabajo (Brasil).

La ley brasileña contempla como límite máximo de duración del contrato de aprendizaje a los 24 meses. Esto representa una reducción respecto del régimen anterior (bajo los anteriores Decreto Ley 5.091 y 5.452) que extendían el tope máximo hasta los 36 meses.

Por parte de Perú, la LMFL establece límites temporales para el uso de los convenios de modalidades formativas. Así, en algunos casos se fija un plazo especificado (por ejemplo: un año como tope máximo para la práctica profesional, salvo que el centro educativo exija un plazo mayor; y un año prorrogable a un año más, en el caso del convenio de actualización para la reinserción laboral) o determinado bajo parámetros razonables. Dichos parámetros bien pueden ser amplios, como ocurre con la duración proporcional de la práctica pre profesional con respecto a la duración de la formación y el nivel de la calificación de la ocupación; o pueden estar delimitados bajo plazos más o menos determinados. Esto último ocurre en la capacitación laboral juvenil, que impone plazos no mayores a seis meses para labores poco complejas (prorrogables a seis meses adicionales) o hasta veinticuatro meses en el caso de labores más calificadas y complejas.

\subsubsection{Limitación de la edad mínima para ser beneficiario de los contratos formativos}

En la legislación brasilera advertimos la existencia de parámetros para la determinación de los grupos etarios beneficiarios del contrato de aprendizaje. Así, se señala que los aprendices a ser contratados deben encontrarse preferentemente dentro de los catorce y dieciocho años. Sin embargo, se reconoce que la edad para el aprendizaje será de dieciocho a veinticuatro años para los casos donde se tenga que las actividades a desarrollarse pudieran exponer a los aprendices a insalubridad o peligrosidad ineludibles, sin opciones a realizar las labores en un ambiente simulado.

Cabe acotar que, en el caso de las personas con discapacidad, el límite de edad es inexistente, lo que supone una forma de tutela específica de parte de la legislación brasilera en el ámbito estudiado.

El legislador peruano, por su parte, reconoce que las diversas modalidades formativas están orientadas a diversos grupos etarios, elemento que puede o no combinarse con los estudios que se hayan cursado para configurar los requisitos aplicables a cada uno de estos tipos de convenio. Así, por ejemplo, en el caso de los convenios de formación se prevé que los beneficiarios deben haber cumplido al menos los 14 años y haber superado los estudios primarios. En el "convenio de pasantía", en cambio, se exige 
que el beneficiario tenga 14 años o más y que se encuentre en los últimos grados del nivel de educación secundaria. Mientras que en la capacitación laboral juvenil se exige que los beneficiarios tengan entre 16 y 23 años y que ellos no hayan culminado la educación básica, o que, habiéndola terminado, no se sigan estudios técnicos o universitarios.

Respecto del aprendizaje con predominio en el centro de formación profesional (prácticas pre profesionales y profesionales) la norma peruana no fija una edad mínima ni máxima, señalándose únicamente que dichas modalidades corresponden, respectivamente, a estudiantes durante su formación o a egresados.

\subsubsection{Porcentaje máximo de beneficiarios}

Un mecanismo que asegura que la participación de personal en formación dentro de las compañías sea proporcionalmente razonable respecto del total de la nómina de trabajadores es, precisamente, la fijación de cuotas o porcentajes. Esto con el fin de que la proporción, fijada normativamente, refleje siempre un índice tolerable de personas en formación dentro del espacio productivo. Esto es, claramente, un mecanismo de protección frente al riesgo de evasión de costos laborales por vía de los contratos formativos.

Así, en Brasil, el Decreto $N^{\circ} 5.598$ establece la obligación de emplear y matricular en los cursos de los Servicios Nacionales de Aprendizaje al número de beneficiarios correspondiente entre el 5\% y $15 \%$ de trabajadores en cada establecimiento, cuyas funciones requieran de formación profesional. Sin embargo, la normativa en este caso toma una previsión importante: además de no considerar a los aprendices ya contratados dentro del universo de trabajadores, que es base de cálculo para determinar al número de aprendices que pueden contratarse, se excluye a los trabajadores que ejecutan labores temporales.

Aquí salta a la vista una diferencia respecto del ordenamiento peruano: para el legislador brasilero, los aprendices ocupan una cuota o porcentaje fijo de personal dentro de la empresa. Conforme con el artículo $429^{\circ}$ de la Consolidación de las Leyes del Trabajo, modificado por la Ley $\mathrm{N}^{\circ}$ 10097, los establecimientos para emplear aprendices deben obtener la autorización correspondiente. De esa forma, tras la culminación del contrato de aprendizaje bajo cualquier causal, los empleadores deben efectuar una nueva contratación de un aprendiz en reemplazo del anterior. 
De acuerdo con lo expresado, las empresas de ese país suelen observar los máximos porcentuales establecidos en la ley para la contratación de aprendices, siendo rarísimos los casos en los que la fiscalización laboral observa una tasa de contratación superior a la autorizada.

En Perú, la LMFL ha previsto que las empresas con más de diez trabajadores puedan suscribir de dos a más convenios de "capacitación laboral juvenil", teniéndose al tope de $20 \%$ de beneficiarios como máximo dentro del área y ocupación específica. Esa misma proporción es la máxima autorizada respecto del número total de trabajadores directos de la empresa. ${ }^{11} \mathrm{Si}$, en cambio, la empresa solamente tiene tres a 10 trabajadores, la ley prevé que solamente podrá suscribirse un solo convenio de propósito formativo.

Una regulación similar prevé la regulación peruana para el convenio de reinserción laboral, el mismo que solo puede suscribirse con una persona si es que la empresa cuenta con más de tres trabajadores y menos de 10. En caso de empresas con mayor número de personal, se exige que el número de los beneficiarios de la actualización para la reinserción laboral no sea mayor al $20 \%$ del total del personal del área u ocupación específica ni al 10\% del total de empleados directos.

\subsubsection{Medidas de prevención de supuestos patológicos en el uso de este tipo de contratos}

Desde el punto de vista regulatorio, existen previsiones que apuntan a evitar el uso fraudulento de los mecanismos reconocidos en la ley. Brasil y Perú optan por caminos normativos distintos, en ese sentido, observándose un mayor control en el primer país sobre posibles situaciones de fraude.

En primer lugar, la norma brasilera prevé que el contrato de aprendizaje culmine al término de su plazo fijado o al cumplir el aprendiz los veinticuatro años. También se establecen supuestos que habilitan la terminación anticipada del contrato de aprendizaje, los mismos que se corresponden con aquellos que tienen lugar en los contratos de trabajo.

Así, se reconocen como causas de culminación anticipada del contrato de aprendizaje al desempeño insuficiente o inadaptación del aprendiz (que se acredita con el laudo de evaluación que emite la entidad calificada por ley), la falta disciplinaria grave (que se remite a las causas justificadas de despido del régimen laboral de los trabajadores), la ausencia injustificada a la escuela que implique la pérdida

${ }^{11}$ Conforme con el artículo 17 de la LMFL, el porcentaje de $20 \%$ puede incrementarse en un $10 \%$ adicional, siempre que las personas adicionales sean jóvenes con discapacidad o jóvenes madres con responsabilidades familiares. 
del año escolar (acreditada por la declaración de la institución de enseñanza) y en caso que el aprendiz solicite el término del contrato.

En los supuestos de extinción del contrato de aprendizaje por desempeño insuficiente, una entidad calificada en formación técnico-funcional metódica es la encargada de acompañar la situación para intentar revertir tal cuadro. Como se deduce, es posible que los aprendices atraviesen por problemas externos al contrato, para lo cual este apoyo puede ser crucial para la mejora de su desempeño.

Otras veces, la función de tal entidad es prevenir que las empresas pretendan utilizar la causal de “desempeño insuficiente" como un artificio para despedir al aprendiz. En tales supuestos, dicha entidad los identifica para evitar el uso arbitrario de esa facultad, pudiendo informar de tales casos a la fiscalización laboral para su intervención.

Otras veces, durante la fiscalización, cuando el inspector del trabajo notifica que la empresa presente los contratos de aprendices que fueron rescindidos, verifica esos casos de extinción del contrato por desempeño insuficiente. Si el problema se produce durante el plazo de la fiscalización, el inspector del Trabajo puede ayudar en la resolución de tal caso, verificando si realmente se consideró un rendimiento insuficiente o si la motivación para la terminación de dicha relación contractual es otra.

En cualquiera de las situaciones descritas, si la Fiscalización entiende a través de las pruebas documentales, que ese motivo fue utilizado para fraudar la legislación y despedir al aprendiz, la empresa será sancionada por la infracción cometida.

No puede dejarse de subrayar que, en el empleo público, los aprendices tienen ciertas particularidades. El artículo 5 del Decreto $\mathrm{N}^{\circ} 5.598$ establece que las disposiciones que regulan el contrato de aprendizaje, "en cuanto al vínculo", no se aplican a la persona jurídica de derecho público.

Este precepto se fundamenta en que la única forma de contratación de las personas jurídicas de derecho público es a través de concurso público, no siendo este el presupuesto de la relación contractual del aprendizaje. Así, en casos de nulidad del contrato de aprendizaje, el contratado no podrá ser considerado empleado de empresa pública, porque él no participó en concurso público para ingreso como servidor público. De todos modos, no queda claro si, en la práctica, ello supone alguna forma de tutela resarcitoria (indemnización a pagarse al joven aprendiz por la nulidad deducida) o restitutoria de 
sus derechos (mediante el reconocimiento de algún derecho de preferencia en el concurso público que pueda celebrarse posteriormente).

Luego, se observa que Perú ha establecido ciertas prohibiciones absolutas de contratar a un ex trabajador bajo una modalidad formativa. En otros casos, esa prohibición solamente rige durante un periodo determinado (un año desde el cese, para la reinserción). Sin embargo, en el fondo, la persona en formación que considere que la modalidad formativa celebrada estuvo desnaturalizada, podrá acceder a la justicia laboral para cuestionar dicha vinculación.

Sin embargo, la práctica jurisdiccional evidencia el extendido uso de las modalidades formativas con el fin de abaratar los costos del personal. En la jurisprudencia constitucional se ha afirmado el concepto por el cual la asignación de funciones distintas a las contenidas en el plan formativo del beneficiario de una modalidad formativa, lo que puede ocurrir respecto de funciones adicionales a las contenidas en el plan de formación ${ }^{12}$; funciones de dudosa calidad formativa; o incluso, la asignación de funciones de sustitución de otros trabajadores cuyos vínculos entraban en suspensión (por vacaciones u otros motivos) (TCP 2012b: Considerandos 4 y 5).

El máximo intérprete de la Constitución en Perú también se ha pronunciado en casos de recontratación de ex trabajadores bajo modalidades formativas. En tales casos, se ha analizado el carácter de las labores realizadas, comparándose a los servicios prestados bajo un contrato de trabajo y los prestados bajo una modalidad formativa (TCP 2009: Considerandos 3 a 6). El razonamiento inverso también ha sido expuesto, de tal forma que cuando se ha advertido que los servicios prestados durante la vigencia de un convenio formativo y una posterior relación laboral eran sustancialmente las mismas, se ha considerado al primer tramo contractual como una relación de trabajo (TCP 2012a: Considerando 3.3.4.).

Los excesos permanentes y bien conocidos de la jornada de personas bajo formación profesional en ciertas actividades económicas (estudios de abogados y en el ámbito de la salud) motivó a que se emita el Decreto Supremo 003-2008-TR, cuyo artículo $1^{\circ}$ califica como supuesto de desnaturalización del contrato de modalidad formativa, sancionándose a este exceso como supuesto de fraude y atribuyéndose al vínculo laboral la característica de un contrato de trabajo.

\footnotetext{
${ }^{12}$ En ese sentido, el Tribunal Constitucional peruano ha resuelto tratando a supuestas culminaciones de contratos formativos como despidos arbitrarios, ordenando la reposición de demandantes que habían suscrito modalidades formativas — pero que realizaban labores distintas a las inicialmente asignadas - estableciéndose contratos de trabajo a plazo indeterminado. Así, puede consultarse la STC 827-2011-PA/TC de 21 de junio de 2011, Considerandos 3 a 6 .
} 
De otro lado, legislador peruano reconoce que las modalidades formativas pueden ser mal utilizadas para disfrazar relaciones de trabajo encubiertas. En esa medida, se sanciona con la nulidad de los convenios suscritos y el encausamiento del vínculo jurídico a una relación de trabajo a plazo indeterminado a los siguientes supuestos, sin perjuicio de las multas administrativas que puedan imponerse (incisos 1 a 7 del artículo 51 de la LMFL):

- La inexistencia del convenio de modalidad formativa debidamente suscrito.

- La falta de capacitación en la ocupación específica y/o el desarrollo de actividades del beneficiario ajenas a la de los estudios técnicos o profesionales establecidos en el convenio.

- La continuación de la modalidad formativa después de la fecha de vencimiento estipulado en el respectivo convenio o de su prórroga o si excede el plazo máximo establecido por la Ley.

- Incluir como beneficiario de alguna de las modalidades formativas a las personas que tengan relación laboral con la empresa contratante, en forma directa o a través de cualquier forma de intermediación laboral, salvo que se incorpore a una actividad diferente.

- La presentación de documentación falsa ante la Autoridad Administrativa de Trabajo para acogerse al incremento porcentual adicional, a que se refieren los artículos 17 y $32 \circ$ para acogerse a otro tipo de beneficios que la Ley o su Reglamento estipule.

- La existencia de simulación o fraude a la Ley que determine la desnaturalización de la modalidad formativa.

- El exceso en los porcentajes limitativos correspondientes.

$\mathrm{Al}$ preverse que sean éstas y no otras las conductas que motivan el tratamiento de la relación jurídica como un vínculo laboral disfrazado, las consecuencias del fraude del acto celebrado no se extienden a otras formas de incumplimiento. El propio legislador ha precisado, por ejemplo, que ni la falta de pago de la subvención económica ni el exceso sobre los topes de jornada ni la falta de cobertura de seguros ni la entrega de la certificación por las actividades desarrolladas suponen, respectivamente, supuestos de desnaturalización (artículo 52 de la LMFL).

Como se ha mencionado anteriormente, la prestación de servicios en exceso sobre la jornada formativa puede acarrear la nulidad del contrato de formación celebrado, reconduciéndose en tal supuesto a un contrato de trabajo. Esta sanción demuestra que para la legislación peruana este incumplimiento da muestra del desinterés de la empresa por adecuar la producción al esquema formativo presuntamente acordado. El tiempo de trabajo se encuentra vinculado, entonces, a la validez propia del contrato de 
formación profesional, sancionándose como conducta fraudulenta a la infracción de las normas que regulan los máximos de jornada. La congruencia de esta sanción con el resto de previsiones en la LMFL ha sido establecida al subrayarse que "el tiempo fuera de la jornada de trabajo no es un tiempo de inactividad, sino un tiempo de formación, esto es, un tiempo productivo social y económicamente" (Balbín 2006: 331). De esta manera, más que una infracción de la norma limitativa sobre la jornada formativa, esta sanción tiene raigambre en el propio fundamento de la LMFL y la promoción de la formación para el empleo.

\section{LA INTERVENCIÓN ADMINISTRATIVA EN LAS PRESTACIONES DE SERVICIOS BAJO MODALIDADES FORMATIVAS}

El Ministerio de Trabajo elabora la Clasificación Brasileña de Ocupaciones, que, en buena cuenta, es un sistema de información sobre empleos, contenidos del trabajo y clasificación de niveles de competencias y la diversidad de las tareas.

Asimismo, dicha autoridad administrativa tiene encargado por ley el organizar un registro nacional de entidades cualificadas en formación técnico-profesional metódica y disciplinar la compatibilidad entre el contenido y la duración del programa de aprendizaje, con miras a garantizar la calidad técnico profesional.

La autoridad de trabajo asume también protagonismo, tanto en la definición de los contenidos básicos de la formación como en la fiscalización de cuotas y condiciones de trabajo e inclusive en el monitoreo de los ex aprendices.

En cuanto al control ejercido por la Secretaría de Inspección del Trabajo, la fiscalización laboral es desarrollada por equipos de inspectores de trabajo. Los boletines de aprendizaje profesional publicados por el Ministerio de Trabajo de Brasil indican que se han intensificado las fiscalizaciones sobre las empresas obligadas a contar con una cuota de aprendices. Esta labor administrativa se efectúa principalmente desde medios electrónicos, tomando como base la información declarada por el propio empleador. ${ }^{13}$ Tal como resalta Leite, esta estrategia es combinada con otras formas de intervención de

\footnotetext{
${ }^{13}$ En Perú, esta forma de fiscalización es empleada por la SUNAFIL desde el año 2016 para determinar el cumplimiento o incumplimiento de las empresas obligadas por la ley a implementar una cuota de personal con discapacidad. Este detalle es importante a fin de establecer una posible forma de control más intensificado sobre las relaciones de formación para el trabajo dentro del ordenamiento peruano, lo que podría tomar como base a la experiencia brasilera sobre la fiscalización electrónica, conjugada con la propia existente.
} 
la autoridad administrativa de trabajo sobre las relaciones de formación profesional: la exploración hacia nuevos sectores que puedan "absorber" aprendices y la articulación con otras acciones que se enfocan al grupo etario sobre el que se busca incidir, previniéndose situaciones de debilidad identificadas (Leite 2015: 69). Así, por ejemplo, se han registrado casos de menores que, proviniendo del trabajo infantil, se insertaron en un proyecto piloto (Pronatec Aprendiz) para su inserción en cursos profesionales.

Lo que es importante advertir aquí es que la inspección del trabajo no solamente efectúa un control orientado a determinar el cumplimiento o no de la legislación laboral. Se ocupa de velar por el funcionamiento del sistema de formación, cosa que se evidencia — por ejemplo- en el artículo 13 del Decreto $\mathrm{N}^{\circ}$ 5.598, cuando establece que es la inspección del trabajo quien determina la insuficiencia de cursos o vacantes de los programas ofrecidos por el Servicio Nacional de Aprendizaje, a fin de determinar la validez de su sustitución por otros organismos cualificados de formación técnica y profesional. Hoy en día, una función como la descrita es impensable en Perú, donde la inspección del trabajo enfrenta barreras jurídicas (falta de normas que regulen una competencia fiscalizadora sobre temas formativos, puramente) y fácticas (la desproporción entre el número de inspectores de trabajo y el número de casos a los que deben avocarse). Sin, embargo, consideramos que el ejemplo ofrecido en este caso por la legislación laboral brasilera permite suponer que la inspección del trabajo puede, a título propio o en sinergia con otras entidades competentes en materias de formación y educación, impactar en el incentivo al cumplimiento de las normas que se refieren a la formación profesional.

Entre los supuestos más frecuentes que aborda la inspección del trabajo se presentan investigaciones respecto a los servicios prestados, ya que lo más común es la desviación de la función planificada. El programa de Aprendizaje es relativo a una actividad y en la práctica la empresa exige que el aprendiz preste otro tipo de servicios.

En cuanto a los incumplimientos en general de la Ley del Aprendizaje, lo que más se observa en la fiscalización laboral es la falta contratación de los aprendices, incumpliendo el cumplimiento de la cuota legal mínima. En segundo momento, lo que más se observa es el incumplimiento de las horas teóricas mínimas. Muchas empresas exigen que el aprendiz trabaje más en la parte práctica en detrimento de la formación teórica. A menudo, la Fiscalización percibe que el cumplimiento del mínimo del 30\% de la carga horaria total del programa de Aprendizaje que debería destinarse a la parte teórica no es cumplida, siendo esas horas destinadas a la parte práctica. 
Distinto es el caso de la Autoridad Laboral en Perú. La función más importante que la Administración del Trabajo ejerce en esta materia es la de formular y desarrollar los instrumentos de política y lineamientos que promueven las modalidades formativas. Esta función está dentro de la competencia de la Dirección General de Formación Profesional y Capacitación Laboral, un órgano de línea del Viceministerio de Empleo del MTPE.

El MTPE interviene a través de capacitaciones de corta duración ofrecidas a la población para la mejora de sus competencias, facilitando su inserción en el trabajo. Así, en la ejecución de programas piloto, se ha introducido un enfoque dual que se fundamenta en el "enfoque por competencias" de la capacitación y con resultados parciales, el mismo que resulta congruente con las políticas más recientes del Sector Educación del país.

Por otro lado, es el Sistema de inspección del trabajo el encargado de establecer los posibles incumplimientos a las normas que protegen a los beneficiarios de las modalidades formativas. ${ }^{14}$ Sobre el particular, la Resolución Ministerial No 140-2013-TR, del 12 de agosto de 2013, aprobó el Protocolo de Actuación Inspectiva en Materia de Modalidades Formativas Laborales, el mismo que contempló una serie de lineamientos para cautelar los derechos de las personas contratadas bajo dichos convenios ${ }^{15}$. De detectarse incumplimientos a las normas que establecen los derechos de los beneficiarios de las modalidades formativas o situaciones de uso fraudulento de tal forma de contratación, se iniciaría un procedimiento sancionador a través del cual podría imponerse una multa administrativa (sin perjuicio de la tutela jurisdiccional que podría activar el prestador de servicios).

En la vía administrativa, las multas previstas en el Reglamento de la Ley 28806, Ley General de Inspección del Trabajo (aprobado por el Decreto Supremo 19-2006-TR) tienen por objeto el desincentivar malas prácticas de los empleadores, estableciéndose la graduación de las multas según el tipo de empleador (distinguiéndose entre microempresas, pequeñas empresas y el resto de empresas) y de acuerdo con la calificación que las normas efectúan sobre la intensidad de las infracciones (leves, graves y muy graves).

\footnotetext{
${ }^{14}$ La facultad fiscalizadora es ejercida en el Perú por dos entidades. Por un lado, la Superintendencia Nacional de Fiscalización Laboral (SUNAFIL), autoridad central en funciones desde el año 2014, que actúa en las regiones del país donde ya está implementada. Por otro lado, los gobiernos regionales, con facultades residuales (algunas microempresas y todos los empleadores donde la SUNAFIL todavía no ha implementado una intendencia regional).

15 Dicho protocolo contiene una serie de pautas que inciden en aspectos formales y no se refieren a la fiscalización del cumplimiento de los aspectos formativos. Tan solo se hace alusión a la congruencia entre la ocupación prevista en el convenio suscrito con las actividades a desarrollarse por el beneficiario de la modalidad formativa.
} 
Así, el Reglamento de la Ley General de Inspección del Trabajo tipifica como faltas administrativas punibles a las siguientes:

a) El incumplimiento de deberes formales o documentales se considera como "infracción leve" siempre que no estén tipificados como infracciones graves o muy graves (artículo 38). Son ejemplos que este cuerpo normativo propone a la falta de registros especiales de modalidades formativas debidamente autorizados por la autoridad competente (artículo 39.1); exceder los límites de contratación legalmente previstos (artículo 39.3); incumplir las obligaciones en materia de formación (artículo 39.4); no proporcionar las facilidades para que el beneficiario de las modalidades formativas se afilie a un sistema pensionario (artículo 39.5); no emitir los informes requeridos por el Centro de Formación Profesional (artículo 39.6); no otorgar el certificado respectivo (artículo 39.7); o el no presentar a la Autoridad el plan o programa correspondiente dentro de los plazos y con los requisitos establecidos (artículo 39.8).

b) Se considera como una falta "muy grave" la falta de registro de personal contratado bajo modalidades formativas laborales (artículo 25.20).

c) Se considera como infracción "muy grave" la falta de pago íntegro y oportuno de la subvención y beneficios derivados (artículo 40.1); el incumplimiento de las normas referidas al tiempo de trabajo (artículo 40.2); la no cobertura de enfermedades o accidentes de trabajo que pueden sufrir los beneficiarios de las modalidades formativas, así como el no asumir el costo de las contingencias por falta de aseguramiento (artículo 40.3 y 40.4); la presentación de documentación falsa para acogerse al incremento de los límites de contratación (artículo 40.5); la falta de un plan o programa correspondiente a la modalidad formativa bajo la cual se contrata a los beneficiarios (artículo 40.6); el uso fraudulento de las modalidades formativas (artículo 40.7); la falta de celebración de convenios de modalidades formativas por escrito y con los requisitos previstos (artículo 40.8) y el uso de castigo físico y humillante (artículo 40.9).

Tras esta revisión de las conductas sancionadas respecto de la prestación de servicios bajo modalidades formativas, salta a la vista que la inspección del trabajo no es capaz de sancionar el incumplimiento del plan o programa, bastando que el empresario presente la documentación pertinente a fin de que se considere satisfecha esta obligación. Resulta, entonces, criticable que un aspecto tan esencial como es la capacitación dentro de las modalidades formativas quede fuera del ámbito de tutela que se imparte desde el control administrativo. 
Adicionalmente, lo indicado evidencia que el verdadero énfasis existente para la normativa de inspecciones se encuentra en el cumplimiento de las obligaciones de las empresas, referidas a los beneficios propios de las modalidades formativas ("subvenciones", límites a la jornada, etcétera). Esto no hace sino reforzar las sospechas sobre el verdadero objetivo o énfasis existente detrás de esta normativa, ya que las normas sancionadoras parecen privilegiar el control sobre el pago de los beneficios o la limitación de la jornada, por encima del proclamado elemento formativo, que bien podría fiscalizarse en sinergia con los centros de formación.

Otra de las funciones que realiza la SUNAFIL, como ente rector del Sistema de Inspección peruano, es el de difundir los derechos laborales y la normativa. En ese sentido, se reporta que su Intendencia Nacional de Prevención y Asesoría ha efectuado charlas de difusión de las modalidades formativas en universidades e institutos del país (que, dentro de la LMFL, son los centros de formación por excelencia); sin embargo, se reconoce que este tema tiene una relevancia menor dentro de las relaciones laborales, dada la existencia de problemas más acuciantes, como son la informalidad laboral y las afectaciones a derechos fundamentales que se vinculan a dicha situación.

\section{PERÚ: UN ANÁLISIS SOCIO JURÍDICO QUE VA MÁS ALLÁ DE LASS REGLASS}

Ya centrándonos en el caso peruano, resulta importante medir la evolución de la población juvenil involucrada en los últimos años en alguna modalidad de formación laboral, de modo que podamos evaluar el impacto que tiene en el mundo del trabajo peruano. En el gráfico 1 se muestra dicha evolución entre el 2013 al 2018 conforme a la información publicada por el Ministerio de Trabajo.

Lo primero que llama la atención es el crecimiento sostenido de personas que participan en alguna modalidad formativa laboral, así entre 2013 y 2018 se incrementó su participación en 49\%, es decir, en los últimos 7 años del período analizado se incorporaron diez mil nuevos jóvenes. Esto significa que cada vez más peruanos estarán involucrados en modalidades formativas laborales, resaltando, con ello, la importancia de la que goza en una política laboral de empleo juvenil. 


\section{Gráfico 1 Perú: Evolución de la Modalidad Formativa Laboral en el sector privado 2013-2018}

\section{Promedio anual de modalidades formativas laborales en el sector privado 2013-2018}

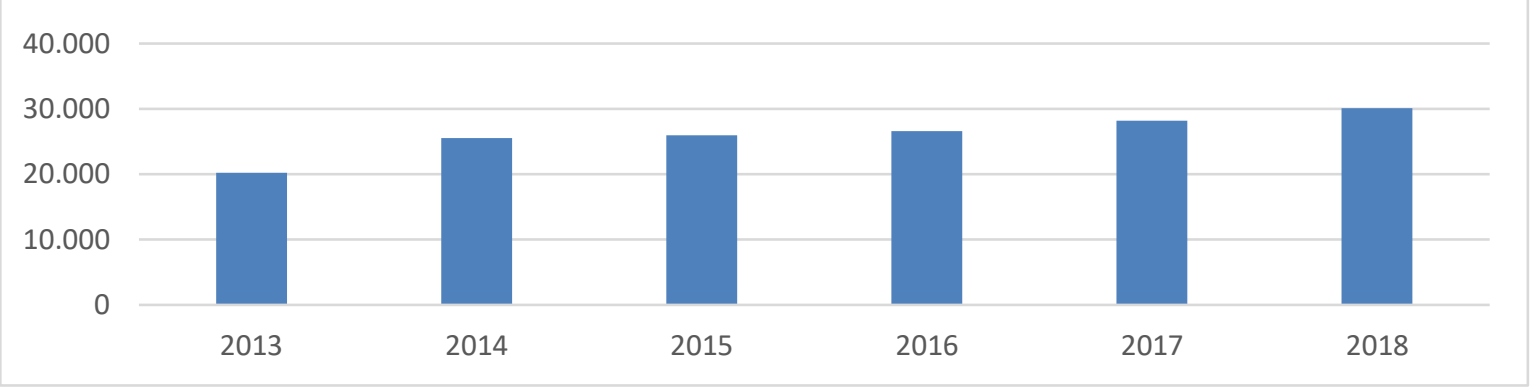

Fuente: Anuarios estadísticos del Ministerio de Trabajo (2013-2018)

Elaboración: Miguel F. Canessa Montejo

Si bien la evolución del crecimiento sostenido del uso de modalidades formativas laborales es significativa, este resultado debe ser comparado con la fuerza laboral juvenil (jóvenes ocupados y desempleados), lo que permite mensurar su impacto sobre la población a la que se pretende beneficiar. Para ello se compara en el cuadro 1 la población económicamente activa de los jóvenes entre los 14 a 29 años de edad (en principio, el universo de jóvenes que puede acogerse a alguna modalidad formativa laboral) y la evolución del promedio anual de los jóvenes registrados en modalidades formativas laborales.

Conforme al cuadro la significancia es pobrísima. Si bien el crecimiento sostenido de los jóvenes en modalidades formativas laborales es relevante. Sin embargo, cuando se le compara con el universo de jóvenes de la población económicamente activa entre 14 a 29 años de edad, apenas representan entre el $0.5 \%$ al $0.6 \%$ en los últimos años. Esto denota que la huella de las modalidades formativas laborales impulsada por el Estado peruano sobre el empleo juvenil es escasa. Lo que plantea su reformulación si pretende responder a una política laboral de empleo que se enfoque de manera privilegiada sobre dicho grupo etario.

Si bien estos porcentajes indican una escasa participación dentro del mercado de trabajo, es justo reconocer que se refiere a los convenios de modalidades formativas efectivamente registrados ante la autoridad, lo que de facto representa un doble filtro de legalidad. Por un lado, supone que la empresa pertenece al sector formal; y, por otro lado, que la modalidad formativa laboral se ha celebrado conforme a ley. 
Cuadro 1 Perú: Comparación entre PEA de 14 a 29 años de edad y jóvenes en modalidades formativas laborales (2014-2018)

\begin{tabular}{|l|l|l|l|l|l|}
\hline Indicadores & $\mathbf{2 0 1 4}$ & $\mathbf{2 0 1 5}$ & $\mathbf{2 0 1 6}$ & $\mathbf{2 0 1 7}$ & $\mathbf{2 0 1 8}$ \\
\hline PEA de 14 a 29 años de edad & $5^{\prime} 268,300$ & $5^{\prime} 139,900$ & $5^{\prime} 166,500$ & $5^{\prime} 188,900$ & $5^{\prime} 158,600$ \\
\hline Jóvenes en modalidades formativas laborales & 25,546 & 25,964 & 26,597 & 28,234 & 30.071 \\
\hline
\end{tabular}

Fuente: INEI y MTPE

Elaboración: Miguel F. Canessa Montejo

En 2016 la Autoridad Nacional del Servicio Civil (en adelante, SERVIR) señaló que el número de beneficiarios de las modalidades formativas declarados en planilla era de al menos treinta y tres mil personas declarados en la planilla electrónica del Ministerio de Trabajo y Promoción del Empleo (en adelante, MTPE) a nivel nacional, en los sectores público y privado formal. No obstante, SERVIR reconoce que esto puede expresar un sub registro de dichas modalidades, pues es sabido que la población total de potenciales beneficiarios de ese tipo de contratación es de al menos doscientos veintiún mil personas, ya que la realización de prácticas pre profesionales constituye un requisito exigido por las universidades peruanas para la obtención del grado académico de bachiller (Servir 2016: 1). En otras palabras, tampoco resulta significativo para el grupo de jóvenes universitarios o de institutos superiores.

La LMFL y su RMFL regulan siete tipos de contratos para las modalidades formativas formación profesional, teniendo todos ellos participación diversa dentro de la distribución ese porcentaje. En el cuadro 2 se distribuye las modalidades formativas laborales registradas en la planilla electrónica del MTPE de los años 2013 y 2015, aunque teniendo presente que los contratos registrados de 2015 incluyen a sus prórrogas, por lo que las cifras no pueden ser directamente comparadas. Dentro de estas siete categorías contractuales incluye al aprendizaje que se celebra con el Servicio Nacional de Adiestramiento en Trabajo Industrial (SENATI), la entidad pública responsable en proporcionar formación profesional y capacitación a los trabajadores de las actividades productivas consideradas dentro del rubro de las industrias manufactureras y actividades industriales de instalación, reparación y mantenimiento.

Teniendo presente lo señalado, observamos que las modalidades formativas con mayor significancia son las prácticas pre profesionales y las prácticas profesionales, ambas representan la inmensa mayoría (no menos del 80\%). Mientras que las demás modalidades tienen escasa representatividad. Solo esto conduce a postular que debe plantearse una profunda modificación en la regulación de los contratos, ya sea reduciéndolos o modificándolos sustancialmente. 
Cuadro 2 Perú: Distribución de las modalidades formativas laborales según contrato 2013-2015

\begin{tabular}{|l|c|c|}
\hline Modalidades formativas & Convenios registrados 2013 & Convenios registrados 2015 \\
\hline Prácticas pre profesionales & 11,218 & 35,242 \\
\hline Prácticas profesionales & 5,350 & 20.839 \\
\hline Aprendizaje con predominio en la empresa & 2,079 & 1,850 \\
\hline Capacitación laboral juvenil & 827 & 47 \\
\hline Pasantía en la empresa & 119 & 14 \\
\hline Reinserción laboral & 13 & 5 \\
\hline Docente con convenio de pasantía & 10 & 60.506 \\
\hline TOTAL & 20.178 & 47 \\
\hline
\end{tabular}

Fuente: Cuadros (2016: 81) y SERVIR (2006: 2)

Elaboración: Miguel F. Canessa Montejo

También este cuadro puede explicarnos las movilizaciones de los jóvenes contra la llamada "Ley Pulpín". Recordemos que las movilizaciones provinieron masivamente desde los jóvenes universitarios y de institutos superiores que suscriben los contratos de prácticas pre profesionales y profesionales, respectivamente. La referida norma se planteó como objetivo facilitar el acceso del empleo de los jóvenes al mercado de trabajo, considerando que su falta de experiencia y habilidades no resultaba atractiva en su contratación. Por supuesto, una política laboral de promoción del empleo debe considerar el escenario del mercado laboral y las dificultades que sufren los distintos grupos para conseguir un empleo decente. Pero en el caso de la Ley del Régimen Laboral Juvenil derogada se adoptó como criterio prolongar temporalmente los contratos de prácticas (pre profesionales y profesionales) y flexibilizar la contratación, lo que trasluce un simple abaratamiento de los costos laborales para promover la contratación de los jóvenes, sin enfocarse en los aspectos estructurales de la falta de empleo juvenil. Los jóvenes interpretaron que la Ley buscaba perennizar una situación jurídica que de por sí rechazaban, por lo que las movilizaciones tuvieron como objetivo la derogación de la norma, lo que consiguieron ante la sorpresa de los empresarios y los políticos.

Por extensión, el rechazo de la Ley Pulpín evidencia que tampoco la actual regulación de la LMFL en sus dos modalidades predominantes recibe el beneplácito del grupo beneficiado —los jóvenes-. Esto nos lleva a analizar a la propia regulación de las modalidades formativas laborales.

${ }^{16}$ Los convenios registrados incluyen sus prórrogas, lo que explica que las cifras comparadas en el cuadro se tripliquen. 


\section{XLABORJUR|5

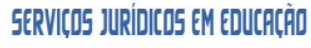

\section{PROPUESTA DE MEJORA DE LA LEY DE MODALIDADES FORIMATIVAS LABORALES DE PERÚ}

Nos parece que existen tres grandes aspectos que requieren abordarse para la reforma de la LMFL. En primer lugar, establecer que las modalidades formativas tienen un carácter laboral, por lo que debe derogarse la regulación que lo excluye. En segundo lugar, asegurar la fiscalización estatal sobre los contratos y el monitoreo de los planes de aprendizaje y capacitación tanto en los centros de aprendizaje y las empresas. En tercer lugar, obligar a los centros de formación en su involucramiento en el control de los planes de aprendizaje y capacitación.

\subsection{La necesaria "laboralización" de las modalidades formativas y su control administrativo}

Es preciso recordar que la Constitución Política del Perú establece, en su artículo 22, que: "El trabajo es un deber y un derecho. Es base del bienestar social y medio de realización de una persona". Asimismo, en su artículo $27^{\circ}$, establece que: "La ley otorga al trabajador adecuada protección contra el despido arbitrario". Este sustento, que ha sido repetido por el Tribunal Constitucional peruano al analizar casos en los que se ha determinado la desnaturalización de cierta modalidad formativa, debe rescatarse para una evaluación global de esta forma de contratación.

Siendo el contrato de formación en Perú que se define por la prestación de servicios y que se inserta de forma decidida dentro de la facultad directriz del empresario, el tratamiento laboral de esta forma de vinculación es conceptualmente sostenible y fácticamente verificable.

Esta extensión del Derecho del Trabajo hacia las relaciones formativas puede ser introducida en la agenda de discusión política del país a partir de la conformación de una agenda elaborada con participación del gobierno peruano, gremios empresariales diversos y organizaciones de jóvenes, los mismos que han demostrado un gran dinamismo en recientes debates coyunturales sobre las reformas de la legislación laboral. Una mirada al caso brasilero debiera auxiliar a comprobar que el reconocer a los aprendices como trabajadores no enerva la naturaleza formativa del vínculo, si es que ella tiene los ajustes necesarios.

Asimismo, mientras que la LMFL mantenga una exclusión, el ordenamiento jurídico peruano mantendrá un parámetro bajo de protección laboral que podría servir de sustento para nuevas tendencias reformistas que actualmente ya buscan reducir los estándares de tutela que la legislación establece bajo el pretexto de incrementar el empleo formal. 


\subsection{El control estatal sobre los contratos formativos}

El actual esquema peruano delega el control de los planes de aprendizaje y capacitación a las empresas, lo que resulta un problema de cara a la eficacia de estas normas (salvo que, ante la violación de algún derecho, el beneficiario formule una denuncia ante el sistema de inspección del trabajo, supuesto más bien atípico).

Con la simplificación administrativa aprobada por el Decreto Legislativo No 1246, el control formal ex ante (registro de los convenios formativos ante la autoridad administrativa) ha desaparecido, mutándose a un sistema de declaración informática. Es entonces momento de revisar las formas de fortalecer y normalizar el control ex post que ejerce la administración del trabajo a través de la inspección laboral. En ese sentido, de la mano con la extensión de la legislación laboral a las relaciones de formación profesional, las autoridades que intervienen en el Sistema de Inspección del Trabajo (la SUNAFIL, el MTPE y los gobiernos regionales) podrían verse más incentivadas a ejercer una supervisión más permanente y visible sobre este ámbito. De esa manera, nueva normativa sobre este tema podría fijar como obligación sectorial el establecer un número determinado de operativos de fiscalización de las relaciones de empleo formativo, en coordinación con otras entidades.

Es posible identificar en la experiencia de la inspección del trabajo del Brasil a formas de organización efectivas que, con dinamismo y composición plural, permita acceder a un control real de los contenidos y aplicación de los respectivos planes de formación. En un esquema de fiscalización electrónica, por ejemplo, grupos de trabajo ad hoc conformados por representantes de la Intendencia de Inteligencia Inspectora de la SUNAFIL y otros de sectores vinculados (Ministerio de Educación, Ministerio de la Producción, etcétera) podrían arribar a formas concretas de abordaje de las problemáticas que se deben superar con una formación profesional adecuada y sobre la que se ejerza un control eficiente (preventivo y reactivo).

\subsection{El involucramiento de los centros de formación}

El actual esquema peruano delega el control de los planes de aprendizaje y capacitación a los centros de formación y a las empresas, lo que resulta un problema de cara a la eficacia de las normas de formación y los planes de adiestramiento respectivos (salvo que, ante la violación de algún derecho, el beneficiario formule una denuncia ante el sistema de inspección del trabajo, supuesto más bien atípico). Por ello, deben subrayarse experiencias como las de la Oficina de Prácticas Pre profesionales y SecigraDerecho de la Pontificia Universidad Católica del Perú. Esta dependencia se encarga de efectuar seguimiento a la formación complementaria de los estudiantes de la Facultad de Derecho de esa 
institución privada, lo que se lleva a cabo en diversas entidades y organizaciones del país. El origen de esta oficina corresponde a la identificación de una problemática específica: en el Perú, la carrera de Derecho es una de las que presenta situaciones de afectación de derechos más generalizadas en el ámbito de las modalidades formativas (limitación de jornada, pago íntegro de la retribución, entre otros). Ante ello, dicha oficina establece formas de comunicación directa con los beneficiarios de las modalidades formativas de tal casa de estudios, emitiendo posteriormente informes periódicos sobre la situación de los estudiantes de Derecho de la mencionada universidad en sus respectivos centros de adiestramiento.

Este proceder podría perfectamente verse articulado con el actuar de la autoridad administrativa de trabajo. Sin embargo, es preciso que la normativa genere los incentivos y previsiones necesarias para replicar esta dinámica y generalizarla en todos los ámbitos donde las modalidades formativas sean utilizadas.

\section{REFLEXIÓN FINAL}

Tras la mirada comparativa a la regulación brasilera, quedan claros puntos de mejora para la regulación de los contratos de formación profesional en el trabajo para el Perú. Existen aspectos que deben ser reformados en distintas intensidades, pero siempre en un norte que nos parece se asienta en el reconocimiento de este tipo de vínculos como laborales.

Una política laboral de promoción del empleo juvenil debe plantearse sobre tres pilares: el respeto de los derechos fundamentales de los jóvenes trabajadores (el trabajo decente), el incremento de la productividad y el incentivo de la contratación de los jóvenes. La reforma integral de la Ley de Modalidades Formativas Laborales puede implementarse de manera armoniosa sobre la base de estos tres pilares. No existe contradicción entre ellas, por el contrario, hay una evidente complementariedad. El Estado peruano no puede escudarse en que los costos económicos de su implementación impiden su materialización. Esto sería conservar la visión errónea sobre el empleo juvenil. No es un costo económico sino una inversión en los jóvenes peruanos. Por ello, la reforma legal debe venir acompañada con recursos para los centros de formación estatal, el Ministerio de Trabajo y la SUNAFIL, de modo que se pueda garantizar que los planes de aprendizaje y de capacitación de la formación laboral se cumplan.

Asimismo, los empresarios peruanos deben modificar el criterio instrumental de que el aprendizaje laboral de los jóvenes en sus empresas es un costo económico y que solo con su abaratamiento o su 
subvención resulta rentable. Sin duda, hay que plantear beneficios tributarios en favor de las empresas que se involucren en la contratación de jóvenes, pero esos beneficios deben venir acompañados con el compromiso empresarial en garantizar el aprendizaje laboral.

El trágico fallecimiento de los dos jóvenes trabajadores debe derribar el muro mental que considera al empleo juvenil en una carga económica. La política laboral no pueden ser medidas aisladas y reactivas ante cada tragedia que se presente en el mundo del trabajo peruano.

\section{BIBLIOGRAFÍA}

ARCE ORTIZ, Elmer (2008). Derecho Individual del Trabajo. Lima: Palestra Editores.

BALBÍN TORRES, Edgardo. (2006). “Jóvenes y trabajo decente” En Laborem. Lima: Sociedad Peruana de Derecho del Trabajo y de la Seguridad Social, No. 6.

CUADROS LUQUE, Fernando (2016). "Situación del mercado de trabajo y costos laborales en el Perú". En: Laborem. Lima: Sociedad Peruana de Derecho del Trabajo y de la Seguridad Social, No. 17.

GOMES, Darcilene (2005). Una desreglamentación del mercado de trabajo brasileño en los años 90 y sus efectos sobre el empleo. Madrid: Universidad Complutense de Madrid, documento de MS Word.

LEITE, Elenice. (2015). El aprendizaje y la preparación de los jóvenes para el trabajo en Brasil. Montevideo: ETD y Oficina de la OIT para países del cono sur de América Latina.

SERVIR (2016). Desafíos de las modalidades formativas laborales en el Perú. Lima: Servir.

TOYAMA MIYAGUSUKU, Jorge (2008). Los contratos de trabajo y otras instituciones de Derecho Laboral. Lima: Gaceta Jurídica.

TRIBUNAL CONSTITUCIONAL DEL PERÚ (2009). STC 006-2007-PA/TC de 31 de agosto de 2009. TRIBUNAL CONSTITUCOONAL DEL PERÚ (2011). STC 827-2011-PA/TC de 21 de junio de 2011. TRIBUNAL CONSTITUCIONAL DEL PERÚ (2012a). STC 1167-2012-PA/TC de 5 de enero de 2012. TRIBUNAL CONSTITUCIONAL DEL PERÚ (2012b). STC 5247-2011-PA/TC de 3 de abril de 2012. TRIBUNAL CONSTITUCIONAL DEL PERÚ. (2013). STC 2725-201 1-PA/TC de 12 de junio de 2013. YAMADA, Gustavo y CÁRDENAS, María de los Ángeles (2009). "Problemática de la reinserción laboral en el Perú". En: Laborem. Lima: Sociedad Peruana de Derecho del Trabajo y de la Seguridad Social, No. 9. 